See discussions, stats, and author profiles for this publication at: https://www.researchgate.net/publication/262952890

\title{
Symbolic dynamics marker of heart rate variability combined with clinical variables enhance obstructive sleep apnea screening
}

Article in Chaos · May 2014

DOI: $10.1063 / 1.4869825$

CITATIONS

22

9 authors, including:

\section{P}

Pedro Saavedra-Santana

Universidad de Las Palmas de Gran Canaria

175 PUBLICATIONS 3,438 CITATIONS

SEE PROFILE

Javier navarro esteva

Hospital Universitario "Doctor Negrín"

20 PUBLICATIONS 57 CITATIONS

SEE PROFILE

Some of the authors of this publication are also working on these related projects:

Sleep EEG Analysis View project

COPD rehabilitation and training View project
Juan L. Navarro-Mesa

Universidad de Las Palmas de Gran Canaria

40 PUBLICATIONS 207 CITATIONS

SEE PROFILE

Andrej Gapelyuk

Humboldt-Universität zu Berlin

49 PUBLICATIONS 591 CITATIONS

SEE PROFILE 


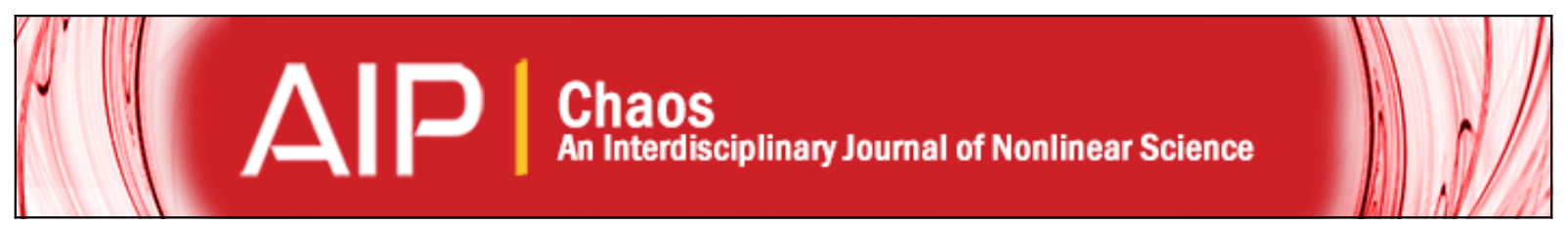

\section{Symbolic dynamics marker of heart rate variability combined with clinical variables enhance obstructive sleep apnea screening}

A. G. Ravelo-García, P. Saavedra-Santana, G. Juliá-Serdá, J. L. Navarro-Mesa, J. Navarro-Esteva, X. ÁlvarezLópez, A. Gapelyuk, T. Penzel, and N. Wessel

Citation: Chaos: An Interdisciplinary Journal of Nonlinear Science 24, 024404 (2014); doi: 10.1063/1.4869825 View online: http://dx.doi.org/10.1063/1.4869825

View Table of Contents: http://scitation.aip.org/content/aip/journal/chaos/24/2?ver=pdfcov

Published by the AIP Publishing

\section{Articles you may be interested in}

Bayesian network modelling of upper gastrointestinal bleeding

AIP Conf. Proc. 1557, 576 (2013); 10.1063/1.4823980

A real-time prostate cancer detection technique using needle insertion force and patient-specific criteria during percutaneous intervention

Med. Phys. 36, 4184 (2009); 10.1118/1.3213453

On the nature of heart rate variability in a breathing normal subject: A stochastic process analysis Chaos 19, 028504 (2009); 10.1063/1.3152008

Announcement: A new feature- "Controversial Topics in Nonlinear Science: Is the Normal Heart Rate Chaotic?" Chaos 18, 020201 (2008); 10.1063/1.2957912

Symbolic dynamics for arrhythmia identification from heart variability of rats with cardiac failures AIP Conf. Proc. 742, 307 (2004); 10.1063/1.1846491

\section{AlP Re-register for Table of Content Alerts}




\title{
Symbolic dynamics marker of heart rate variability combined with clinical variables enhance obstructive sleep apnea screening
}

\author{
A. G. Ravelo-García, ${ }^{1}$ P, Saavedra-Santana,${ }^{2}$ G. Juliá-Serdá, ${ }^{3}$ J. L. Navarro-Mesa, ${ }^{1}$ \\ J. Navarro-Esteva, ${ }^{3}$ X. Álvarez-López, ${ }^{3}$ A. Gapelyuk, ${ }^{4}$ T. Penzel, ${ }^{5}$ and N. Wessel ${ }^{4}$ \\ ${ }^{1}$ Institute for Technological Development and Innovation in Communications (IDeTIC), Universidad de Las \\ Palmas de Gran Canaria, Las Palmas de G.C. 35017, Spain \\ ${ }^{2}$ Department of Mathematics. Universidad de Las Palmas de Gran Canaria, Las Palmas de G.C. 35017, Spain \\ ${ }^{3}$ Pulmonary Medicine Department. Hospital Universitario de Gran Canaria Dr. Negrín, Las Palmas de G.C. \\ 35010, Spain \\ ${ }^{4}$ Department of Physics, Humboldt-Universität zu Berlin, Berlin 10115, Germany \\ ${ }^{5}$ Sleep Center, Charité Universitätsmedizin, Berlin 10117, Germany
}

(Received 31 October 2013; accepted 17 March 2014; published online 27 March 2014)

\begin{abstract}
Many sleep centres try to perform a reduced portable test in order to decrease the number of overnight polysomnographies that are expensive, time-consuming, and disturbing. With some limitations, heart rate variability (HRV) has been useful in this task. The aim of this investigation was to evaluate if inclusion of symbolic dynamics variables to a logistic regression model integrating clinical and physical variables, can improve the detection of subjects for further polysomnographies. To our knowledge, this is the first contribution that innovates in that strategy. A group of 133 patients has been referred to the sleep center for suspected sleep apnea. Clinical assessment of the patients consisted of a sleep related questionnaire and a physical examination. The clinical variables related to apnea and selected in the statistical model were age $\left(\mathrm{p}<10^{-3}\right)$, neck circumference $\left(\mathrm{p}<10^{-3}\right)$, score on a questionnaire scale intended to quantify daytime sleepiness $\left(\mathrm{p}<10^{-3}\right)$, and intensity of snoring $\left(\mathrm{p}<10^{-3}\right)$. The validation of this model demonstrated an increase in classification performance when a variable based on non-linear dynamics of HRV $(\mathrm{p}<0.01)$ was used additionally to the other variables. For diagnostic rule based only on clinical and physical variables, the corresponding area under the receiver operating characteristic (ROC) curve was 0.907 (95\% confidence interval $(C I)=0.848,0.967)$, (sensitivity $87.10 \%$ and specificity $80 \%$ ). For the model including the average of a symbolic dynamic variable, the area under the ROC curve was increased to $0.941(95 \%=0.897$, 0.985), (sensitivity $88.71 \%$ and specificity $82.86 \%$ ). In conclusion, symbolic dynamics, coupled with significant clinical and physical variables can help to prioritize polysomnographies in patients with a high probability of apnea. In addition, the processing of the HRV is a well established low cost and robust technique. (C) 2014 AIP Publishing LLC. [http://dx.doi.org/10.1063/1.4869825]
\end{abstract}

Overnight polysomnography (PSG) is the reference diagnostic test for sleep apnea, but it is expensive, time-consuming, and disturbing. Therefore, it becomes necessary to explore portable recording in order to reduce demands for PSG. The aim of this study is not to replace the gold standard but to avoid unnecessary PSG. Standard methods for heart rate variability (HRV) analysis have already been used in this area. The aim of this investigation was to evaluate the contribution of a non-linear variable, obtained from symbolic dynamics of HRV, to a statistical classifier, integrating clinical and physical variables, to reduce and prioritize demands for polysomnography tests. The validation of the model demonstrated an increase in sensitivity (from $\mathbf{8 7 . 1 0} \%$ to $\mathbf{8 8 . 7 1 \%} \%$ ) and specificity (from $\mathbf{8 0} \%$ to $\mathbf{8 2 . 8 6} \%$ ) when this non-linear dynamics variable was applied to the database of 133 patients.

\section{INTRODUCTION}

The Obstructive Sleep Apnea (OSA) is a respiratory disorder characterized by frequent breathing pauses and a collapse of the pharynx during sleep. If breathing ceases completely, the event is called an apnea. In the case where the breathing does not cease completely but a reduction in the volume of air entering the lungs can be detected, the event is called a hypopnea.

Apneas produce an alteration of the normal sleep architecture via multiple arousals, which cause somnolence during the day, and are associated with increased risks of high blood pressure, myocardial infarction, stroke, and increased mortality rates.

Overnight PSG, the gold standard test for OSA, is a laborious and costly diagnostic tool that is also uncomfortable for the patient and not always available in all the centers. In addition, waiting lists for performing PSG are long resulting in diagnosis and treatment delays for patients with clear symptoms of apnea. For all these reasons, it has become necessary to develop solutions aiming at prioritizing or reducing the number of polysomnographies.

Different methods have tried to analyze different chaotic systems. ${ }^{1-4}$ The suggestion of chaotic behaviour of heart rate variability due to different external influences (e.g., respiration) has already been presented in the past. ${ }^{5}$ For these reasons, we want to test the performance of a variable based on symbolic dynamics of the beat-to-beat intervals obtained from the electrocardiogram (ECG) signal (RR intervals) as new information to insert to the set of existing clinical and physical 
variables. In this paper, it will be shown that a logistic regression model increases in classification performance when the new non-linear symbolic dynamics variable is added.

\section{METHODS}

A group of 133 patients (93 males and 40 females between 18 and 83 years of age) has been referred to the sleep center. All patients were examined by one of two experienced pulmonologists in sleep medicine. From the original 133 subjects database, 36 were excluded because of a limitation in the period of sleep and heart disorders, thus, 97 patients were finally elected for this study.

All recordings contain a single ECG digitized at $200 \mathrm{~Hz}$ with 16-bit resolution (individual recordings vary in length from $230 \mathrm{~min}$ to $485 \mathrm{~min}$ ). Each recording includes a set of reference annotations, one for each $30 \mathrm{~s}$ segment, which indicates the presence or absence of apnea during that segment. These reference annotations were made by human experts on the basis of a complete polysomnography. In order to obtain 1 min scoring, we consider the presence of apnea if one or more sleep breathing pauses appear in any of the two $30 \mathrm{~s}$ epochs.

For each patient, clinical and anthropometric measurements were obtained. An apnea-hypopnea index (AHI) was also evaluated according to the PSG. A diagnosis of OSA was made when the AHI was greater than or equal to ten. In accordance to important epidemiological studies that have looked at the prevalence of OSA in the general population, an AHI index of ten or more is chosen as pathological. ${ }^{6}$

On the evening of the sleep measurement, patients filled out a self administered questionnaire which included 16 questions about symptoms normally associated with OSA. Patients also answered questions about the presence of other diseases as diabetes, hypertension, or heart diseases. In addition, the Epworth sleepiness scale was administered. Moreover, a comprehensive physical examination that included anthropometric measurements such as body mass index (BMI), neck circumference, and waist circumference was undertaken. Similarly, an upper airway exploration was carried out.

A full sleep study was performed consisting of four electroencephalographic channels (two central and two occipital), two leads for electro-oculograms, and a submental electrode for an electromyogram. Thoracic and abdominal movements were detected using two piezoelectric belts. Nasal and oronasal flow were measured by a nasal cannulae, and a thermistor sensor, respectively. Hemoglobin oxygen saturation was continuously recorded. Finally, the study also included a continuous electrocardiographic tracing.

All of these variables were collected and integrated in a computerized system using the software VIASYS Healthcare, Inc., USA. The sleep studies were staged, according to the AASM 2012 (American Academy of Sleep Medicine) criteria $^{7}$ by two trained sleep technicians who were blind to the clinical characteristics of each patient. The sleep studies were subsequently reviewed by a sleep clinician.

\section{Extraction of RR intervals and post processing}

The RR intervals often require the exclusion of artifacts and additional ectopic values (e.g., ventricular premature complexes) so an adaptive filtering procedure for automatic artifact removal was applied. ${ }^{8}$

\section{Variable obtained from symbolic dynamics of the RR intervals}

Heart rate variability originates from the interaction functioning of different control loops in the cardiovascular and the autonomous nervous system and demonstrates a complex behavior that can not be completely described by standard linear analysis in time and frequency domains. ${ }^{9,10}$ Applying nonlinear dynamic methods gives additional information about state of the cardiovascular and the autonomous nervous systems, especially for non- stationary parts of the HRV time series and transient processes where linear methods are not applicable due to a violation of the stationarity assumption.

One of the suitable tools for non-linear HRV analysis is the so called symbolic dynamics method. ${ }^{911-15}$ It conducts a transformation of the initial time series of RR-intervals with a continuous number of levels between the minimum and maximum value of the RR intervals into a sequence of symbols of a given alphabet. ${ }^{9,16,17}$ We use an alphabet of four symbols $\{0,1,2,3\}$ as described in Ref. 9. The full range of

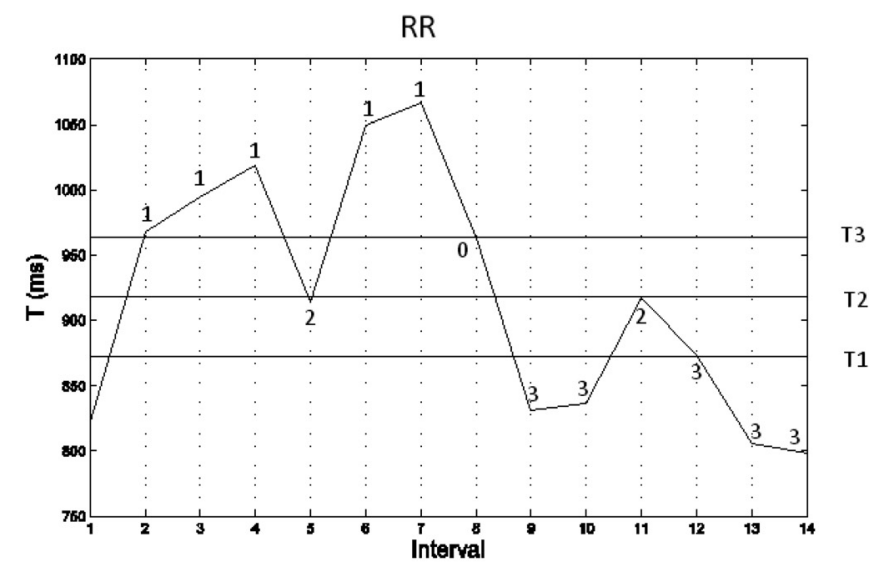

Symbol definition

$$
\begin{aligned}
& \mathrm{T} 3=\mathrm{m}+\mathrm{a} * \mathrm{~m} \\
& \mathrm{~T} 2=\mathrm{m} \\
& \mathrm{T} 1=\mathrm{m}-\mathrm{a}^{*} \mathrm{~m} \\
& \text { 3: } 0<\mathrm{RR}_{\mathrm{n}}<=\mathrm{T} 1 \\
& \text { 2: } \mathrm{T} 1<\mathrm{RR}_{\mathrm{n}}<=\mathrm{T} 2 \\
& 0: \mathrm{T} 2<\mathrm{RR}_{\mathrm{n}}<=\mathrm{T} 3 \\
& \text { 1: } \mathrm{T} 3<\mathrm{RR}_{\mathrm{n}}<\text { infinite }
\end{aligned}
$$

\section{Symbol sequence}

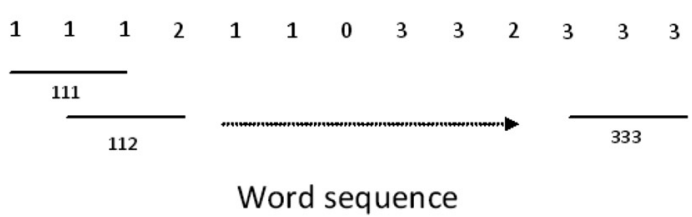

FIG. 1. The basic principle of symbolic dynamics that describes the extraction of symbols from RR intervals and the extraction of word sequences from the symbols series. 


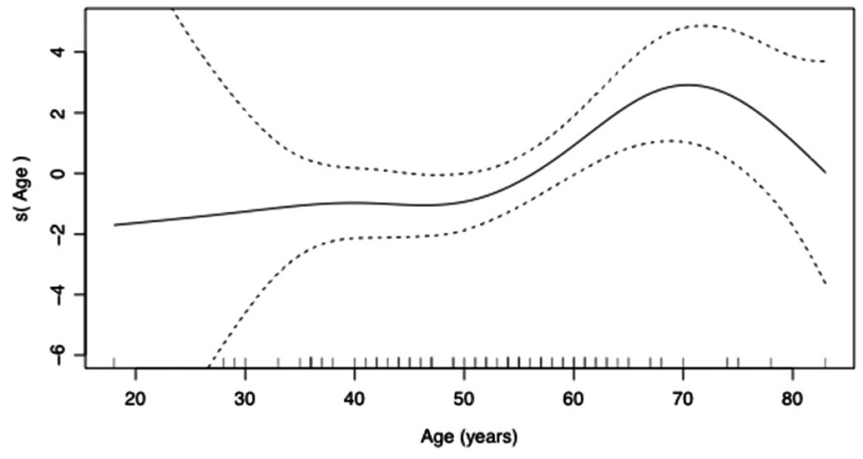

FIG. 2. Non-linear effect of the age on the probability of OSA (- - -95\% CI) (model based only on the clinical and physical variables). The model shows that from the age of $70 \mathrm{yr}$, the probability of OSA decreases.

RR intervals is divided into 4 four partitions by using three thresholds T1, T2, and T3 (see Figure 1)

$$
\begin{gathered}
\mathrm{T} 1=\mathbf{m}-\mathbf{a}^{*} \mathbf{m}, \\
\mathrm{T} 2=\mathbf{m}, \\
\mathrm{T} 3=\mathbf{m}+\mathbf{a}^{*} \mathbf{m},
\end{gathered}
$$

where $\mathbf{m}$ is the mean value of the RR intervals and the parameter $\mathbf{a}$ is a constant which defines a threshold for the symbolic representation. Based on previous experience, we choose a value of $\mathrm{a}=0.05$. The symbols are assigned to each RR interval by applying the following rules:

$$
\begin{array}{ll}
\text { if } \mathrm{T} 2<\mathrm{RR}_{\mathrm{n}}<=\mathrm{T} 3 & \text { then } \mathrm{S}_{\mathrm{n}}=0 ; \\
\text { if } \mathrm{T} 3<\mathrm{RR}_{\mathrm{n}} & \text { then } \mathrm{S}_{\mathrm{n}}=1 ; \\
\text { if } \mathrm{T} 1<\mathrm{RR}_{\mathrm{n}}<=\mathrm{T} 2 & \text { then } \mathrm{S}_{\mathrm{n}}=2 ; \\
\text { if } 0<\mathrm{RR}_{\mathrm{n}}<=\mathrm{T} 1 & \text { then } \mathrm{S}_{\mathrm{n}}=3 .
\end{array}
$$

For further analysis, we consider words constructed from three adjacent symbols. We obtain the next word by shifting the time series to the next symbol. The maximum number of possible different words of length three from our given alphabet is equal to $4^{3}$. There are several approaches to characterize such word sequences. Recently, Cysarz et $a l .{ }^{17}$ have shown that different symbolic dynamics approaches derived from RR intervals time series can be used to evaluate reaction of autonomous nervous system on orthostatic head-up tilt test in healthy subjects.

From the different variables based on linear dynamics and described in Ref. 9, we decided to use WPSUM13 for its information about the presence of an increased heart rate variability that is present in many apnea phases. The variable WPSUM13 describes the percentage of words which contain the symbols " 1 " and " 3 ." Thus, a high value of WPSUM13 contains information about tachycardia or bradycardia present in some apnea phases.

\begin{tabular}{|c|c|c|c|c|}
\hline & \multirow[b]{2}{*}{$\begin{array}{c}\text { Total } \\
\mathrm{N}=97\end{array}$} & \multicolumn{2}{|c|}{ OSA } & \multirow[b]{2}{*}{$\mathrm{P}$} \\
\hline & & $\begin{array}{c}\text { Yes } \\
\mathrm{N}=62\end{array}$ & $\begin{array}{c}\text { No } \\
\mathrm{N}=35\end{array}$ & \\
\hline Age, years & $52.3 \pm 12.0$ & $53.4 \pm 11.7$ & $50.4 \pm 12.6$ & 0.238 \\
\hline Men/Woman, \% & $71.1 / 28.9$ & $80.6 / 19.4$ & $54.3 / 45.7$ & 0.006 \\
\hline Weight, kg & $92.1 \pm 17.6$ & $97.0 \pm 17.1$ & $83.4 \pm 15.2$ & $<0.001$ \\
\hline Height, cm & $169 \pm 10.2$ & $170 \pm 10.4$ & $167 \pm 9.5$ & 0.095 \\
\hline BMI, $\mathrm{kg} / \mathrm{m}^{2}$ & $32.2 \pm 5.2$ & $33.4 \pm 4.9$ & $30.0 \pm 5.0$ & 0.002 \\
\hline Waist circumference, $\mathrm{cm}$ & $112 \pm 12$ & $115 \pm 12$ & $108 \pm 12$ & 0.003 \\
\hline Neck circumference, $\mathrm{cm}$ & $41.1 \pm 3.8$ & $42.9 \pm 3.9$ & $39.3 \pm 3.6$ & $<0.001$ \\
\hline Dips & $10.1(3.8 ; 29.7)$ & $20.9(12.0 ; 46.4)$ & $1.5(0.3 ; 4.5)$ & $<0.001$ \\
\hline Epworth & $11.8 \pm 5.6$ & $13.0 \pm 5.5$ & $9.5 \pm 5.0$ & 0.002 \\
\hline Deviated nasal septum, n (\%) & $30(30.9)$ & $19(30.6)$ & $11(31.4)$ & 0.936 \\
\hline Hypertrophy of nasal turbinates, n (\%) & $13(13.4)$ & $9(14.5)$ & $4(11.4)$ & 0.668 \\
\hline Polyps, n (\%) & $1(1.0)$ & $1(1.6)$ & 0 & 1 \\
\hline Retrognathia, n (\%) & $3(3.1)$ & 0 & $3(8.6)$ & 0.044 \\
\hline Micrognathia, n (\%) & $97(100)$ & $62(100)$ & $35(100)$ & $\ldots$ \\
\hline Dental malocclusion, n (\%) & $19(19.6)$ & $10(16.1)$ & $9(25.7)$ & 0.253 \\
\hline Tonsils, n (\%) & & & & 0.360 \\
\hline Absence & $27(27.8)$ & $16(25.8)$ & $11(31.4)$ & \\
\hline It reaches to palatopharyngeus bow & $39(40.2)$ & $25(40.3)$ & $14(40.0)$ & \\
\hline In palatopharyngeus bow & $18(18.6)$ & $10(16.1)$ & $8(22.8)$ & \\
\hline Beyond palatopharyngeus bow & $13(13.4)$ & $11(17.7)$ & $2(5.7)$ & \\
\hline Fallen Palate (\%) & $46(47.4)$ & $33(53.2)$ & $13(37.1)$ & 0.128 \\
\hline Hypertrophy of the uvula, n (\%) & $34(35.4)$ & $24(38.7)$ & $10(29.4)$ & 0.362 \\
\hline Indentations on the tongue, $\mathrm{n}(\%)$ & $21(21.6)$ & $14(22.6)$ & $7(20.0)$ & 0.767 \\
\hline Abnormal cardiorespiratory exploration, $\mathrm{n}(\%)$ & $5(5.2)$ & $2(3.2)$ & $3(8.6)$ & 0.348 \\
\hline Vital Capacity (\% predicted) & $102(89 ; 113)$ & $101(88 ; 113)$ & $103(91 ; 110)$ & 0.895 \\
\hline Forced expiratory volume in one second (\% predicted) & $99(85 ; 108)$ & $99(88 ; 108)$ & $101(84 ; 104)$ & 0.719 \\
\hline
\end{tabular}

The variable WPSUM13 is summarized in a value for each minute of observation $\left(\mathrm{WP}_{\mathrm{t}}\right)$. We extract one measure for each patient based on the $\mathrm{WP}_{\mathrm{t}}$ calculated in 5 min frames. In order to consider an equal length for all the patients, the

TABLE I. Description of the database in function of the presence or absence of OSA. Data represent mean $\pm \mathrm{SD}$, medians (IQR) or frequencies, and percentages. 
first $n_{W}=230$ min of observation was considered. A six component (feature) vector was defined as follows:

$\mathrm{M}_{1}$ : Mean values of the variable WPSUM13

$\mathrm{M}_{2}$ : 25th percentile, $\mathrm{M}_{2}=\mathrm{P}_{25} \mathrm{WP}_{\mathrm{t}}$

$\mathrm{M}_{3}$ : 75th percentile, $\mathrm{M}_{3}=\mathrm{P}_{75} \mathrm{WP}_{\mathrm{t}}$

$\mathrm{M}_{4}$ : Percentage of $\mathrm{WP}_{\mathrm{t}}$ greater than 0.2

$\mathrm{M}_{4}=\%\left(\mathrm{WP}_{\mathrm{t}}>0.2\right)$

$\mathrm{M}_{5}$ : Percentage of $\mathrm{WP}_{\mathrm{t}}$ greater than 0.4
$\mathrm{M}_{5}=\%\left(\mathrm{WP}_{\mathrm{t}}>0.4\right)$

$\mathrm{M}_{6}$ : Percentage of $\mathrm{WP}_{\mathrm{t}}$ greater than 0.6

$\mathrm{M}_{6}=\%\left(\mathrm{WP}_{\mathrm{t}}>0.6\right)$.

\section{Statistical analysis}

For all the patients analyzed and in each one of the subgroups considered (presence/absence of OSA), categorical variables were summarized as frequencies and percentages,

TABLE II. Questionnaire.

\begin{tabular}{|c|c|c|c|c|c|}
\hline & & \multirow[b]{2}{*}{$\begin{array}{c}\text { Total } \\
\mathrm{N}=97\end{array}$} & \multicolumn{2}{|c|}{ OSA } & \multirow[b]{2}{*}{$\mathrm{P}$} \\
\hline & & & $\begin{array}{c}\text { Yes } \\
\mathrm{N}=62\end{array}$ & $\begin{array}{c}\text { No } \\
\mathrm{N}=35\end{array}$ & \\
\hline \multirow[t]{4}{*}{ Snoring, n (\%) } & & & & & 0.021 \\
\hline & Never & $3(3.1)$ & $1(1.6)$ & $2(5.7)$ & \\
\hline & Sometimes & $6(6.2)$ & $1(1.6)$ & $5(14.3)$ & \\
\hline & Never & $88(90.7)$ & $60(96.8)$ & $28(80.0)$ & \\
\hline Loud snoring, n (\%) & & $70(72.2)$ & $54(87.1)$ & $16(45.7)$ & $<0.001$ \\
\hline \multirow[t]{4}{*}{ Sleep Breathing pauses, n (\%) } & & & & & 0.002 \\
\hline & Never & $15(15.5)$ & $4(6.5)$ & $11(31.4)$ & \\
\hline & Sometimes & $45(46.4)$ & $29(46.8)$ & $16(45.7)$ & \\
\hline & Often & $37(38.1)$ & $29(46.8)$ & $8(22.9)$ & \\
\hline \multirow[t]{5}{*}{ Sleep, breathing crisis, n (\%) } & & & & & 0.204 \\
\hline & Never & $45(46.4)$ & $24(38.7)$ & $21(60.0)$ & \\
\hline & Rarely & $6(6.2)$ & $5(8.1)$ & $1(2.9)$ & \\
\hline & Sometimes & $33(34.0)$ & $23(37.1)$ & $10(28.6)$ & \\
\hline & Often & $13(13.4)$ & $10(16.1)$ & $3(8.6)$ & \\
\hline \multirow[t]{5}{*}{ Tiredness/bad sleep, n (\%) } & & & & & 0.245 \\
\hline & Never & $12(12.4)$ & 8 (12.9) & $4(11.4)$ & \\
\hline & Rarely & $5(5.2)$ & $2(3.2)$ & $3(8.6)$ & \\
\hline & Sometimes & $30(30.9)$ & $23(37.1)$ & $7(20.0)$ & \\
\hline & Often & $50(51.7)$ & $29(46.8)$ & $21(60.0)$ & \\
\hline \multirow[t]{4}{*}{ Nocturia, n (\%) } & & & & & 0.216 \\
\hline & Never & $17(17.5)$ & $10(16.1)$ & $7(20.0)$ & \\
\hline & Once & $50(51.5)$ & $29(46.8)$ & $21(60.0)$ & \\
\hline & Two or more & $30(30.9)$ & $23(37.1)$ & $7(20.0)$ & \\
\hline \multirow[t]{4}{*}{ Hypertension n (\%) } & & & & & 0.152 \\
\hline & Yes & $39(40.2)$ & $27(43.5)$ & $12(34.3)$ & \\
\hline & No & $50(51.1)$ & $28(45.2)$ & $22(62.9)$ & \\
\hline & No answer & $8(8.2)$ & $7(11.3)$ & $1(2.9)$ & \\
\hline Use of anti-hypertension, $\mathrm{n}(\%)$ & & $39(40.2)$ & $26(41.9)$ & $13(37.1)$ & 0.644 \\
\hline \multirow[t]{4}{*}{ Diabetes mellitus, n (\%) } & & & & & 0.132 \\
\hline & Yes & $15(15.5)$ & $12(19.2)$ & $3(8.6)$ & \\
\hline & No & $79(81.4)$ & $47(75.8)$ & $32(91.4)$ & \\
\hline & No answer & $3(3.1)$ & $3(4.8)$ & 0 & \\
\hline \multirow[t]{4}{*}{ Heart disease, $\mathrm{n}(\%)$} & & & & & 0.071 \\
\hline & Yes & $14(14.4)$ & $12(19.4)$ & $2(5.7)$ & \\
\hline & No & $73(75.3)$ & $42(67.7)$ & $31(88.6)$ & \\
\hline & No answer & $10(10.3)$ & $8(12.9)$ & $2(5.9)$ & \\
\hline \multirow[t]{4}{*}{ Arrhythmia, n (\%) } & & & & & 0.801 \\
\hline & Yes & $14(14.4)$ & $8(12.9)$ & $6(17.1)$ & \\
\hline & No & $67(69.1)$ & $43(69.4)$ & $24(68.6)$ & \\
\hline & No answer & $16(16.5)$ & $11(17.7)$ & $5(14,3)$ & \\
\hline Cardiac treatment, $\mathrm{n}(\%)$ & & $13(13.4)$ & $10(16.1)$ & $3(8.6)$ & 0.294 \\
\hline \multirow[t]{4}{*}{ Respiratory disease } & & & & & 0.278 \\
\hline & Yes & $23(23.7)$ & $12(19.4)$ & $11(31.4)$ & \\
\hline & No & $57(58.8)$ & $37(59.7)$ & $20(57.1)$ & \\
\hline & No answer & $17(17.5)$ & $13(21.0)$ & $4(11.4)$ & \\
\hline Treatment for bronchitis & & $16(16.5)$ & $9(14.5)$ & $7(20.0)$ & 0.485 \\
\hline
\end{tabular}




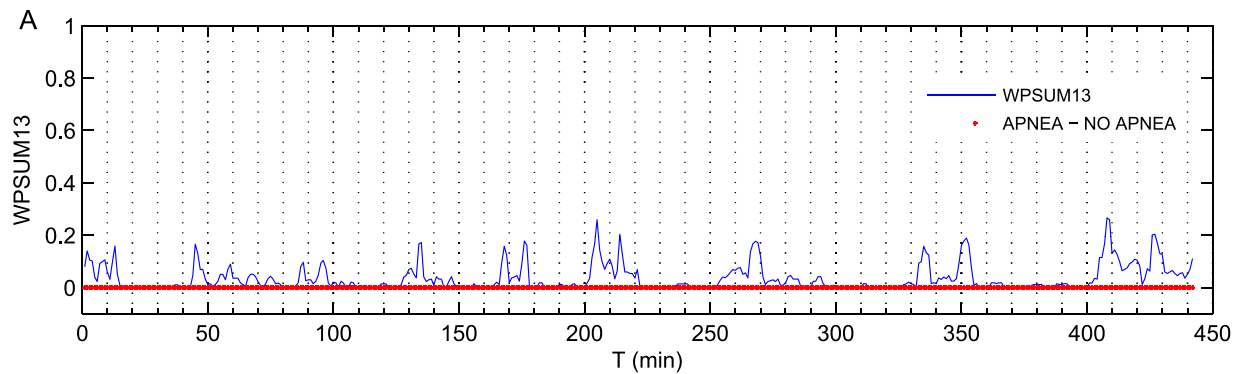

B

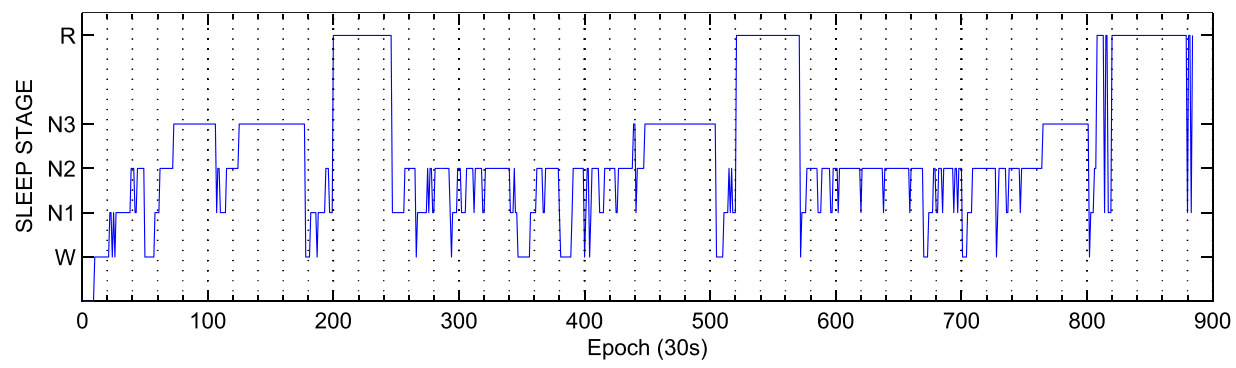

FIG. 3. The variable WPSUM13 and hypnogram for a control recording. (a) represents the dynamic of the variable WPSUM13 every minute. In red asterisk format, the apnea scoring for every minute indicating the absence of apnea the whole night is presented. (b) represents the hypnogram indicating the different sleep stages, wakefulness (stage W), light sleep (stages N1 and N2), deep sleep (stage N3), and REM sleep (stage R). High values of WPSUM13 in REM and Wake transitions can be seen but with lower amplitude than presented in the apnea case (Figure 3). continuous variables as mean and standard deviation (SD) when data followed a normal distribution, or as median and interquartile (25th-75th percentile) range (IQR) when the distribution departed from normality. The percentages were compared using the Chi-square $\left(\chi^{2}\right)$ test, the means by the t-test, and the medians by the Wilcoxon test. In order to obtain diagnostic rules for the OSA, two multivariate logistic analyses were performed. In the first, only clinical variables were included, while the second analysis, additionally included the $W P_{t}$ vector obtained from the RR time series. In each analysis, the best subset of variables was obtained using the complete enumeration algorithm ${ }^{15}$ and the Akaike criterium. ${ }^{18}$ A potential non-linear effect of the age variable was explored using additive logistic regression (Figure 2). The model has the form

$$
\begin{aligned}
\operatorname{logit} \operatorname{Pr}(O S A)= & \beta_{0}+\beta_{1} \cdot N C+\beta_{2} \cdot \text { Epworth }+\beta_{3} \cdot \text { Loud } \\
& + \text { s(age }),
\end{aligned}
$$

where NC represents the neck circumference, Loud is the loud snoring, and $s$ (age) is a function of the age, which is nonparametrically estimated. This model was fitted by penalized likelihood maximization, estimating the smoothing parameters by the procedure of generalized cross-validation. ${ }^{19}$ The logistic models are summarized via the p-values corresponding to the likelihood ratio test and odd ratios, which were estimated by $95 \%$ confidence intervals.

The discriminative values of the probabilities of OSA obtained from each of the models were evaluated by means of the corresponding areas under the receiver operating characteristic (ROC) curves. The cut-off corresponding to the point of ROC curve that minimizes the distance between the curve and the upper left corner (the sum of sensitivity and specificity is maximal) was chosen. For each of the diagnostic rules, the parameters of sensitivity, specificity, positive predictive value, negative predictive value, positive likelihood ratio, and negative likelihood ratio were estimated by means of $95 \%$ confidence intervals. Statistical significance was set at $\mathrm{p}<0.05$. The data analysis was carried out in $\mathrm{R}^{20}$

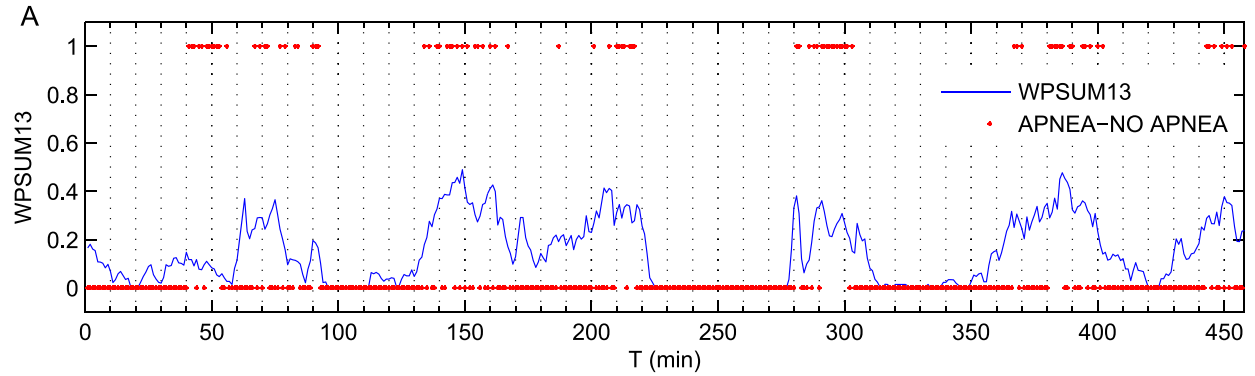

B

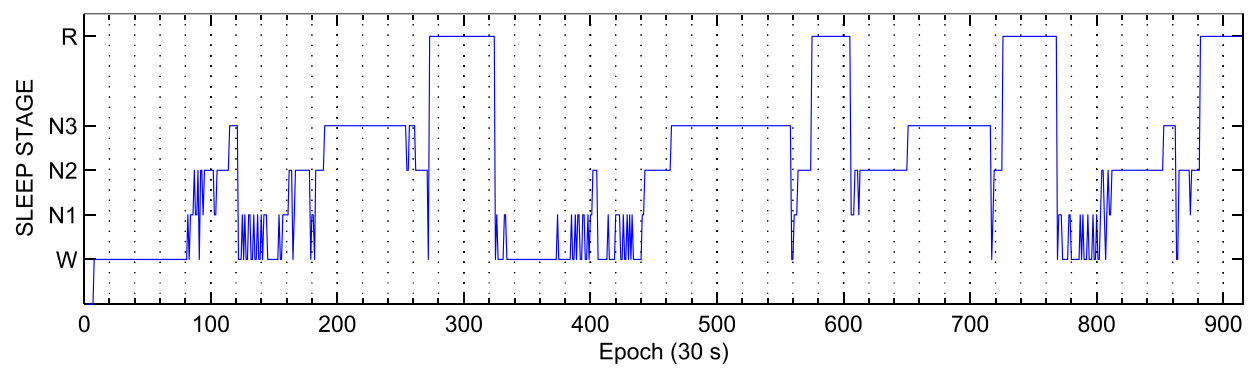

FIG. 4. The variable WPSUM13 and hypnogram for an apnea recording. (a) represents the dynamic of the variable WPSUM13 every minute. In red asterisk format, the apnea scoring for every minute indicating the presence of apnea (value $=1$ ) or absence of apnea (value $=0$ ) is presented. It is observed bigger values of variable WPSUM13 in sleep breathing pauses minutes related to the presence of increased heart rate dynamics than in other minutes. (b) represents the hypnogram indicating the different sleep stages, wakefulness (stage W), light sleep (stages N1 and N2), deep sleep (stage N3), and REM sleep (stage R). Higher values of WPSUM13 can be seen also in REM and Wake transitions. 


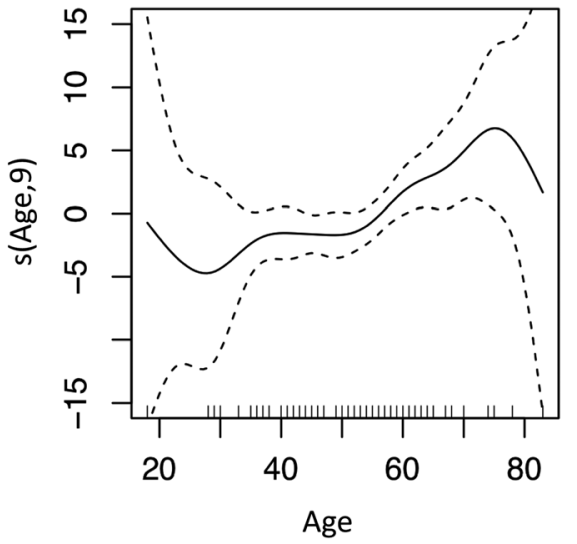

\section{RESULTS}

Univariate analyses of the clinical variables are summarized in Tables I and II.

In Figure 3(a), the dynamic of WPSUM13 in a control subject without sleep breathing pauses in the whole night can be observed. Figure 3(b) shows the hypnogram representing the sleep stages, another influence on heart rate dynamics, in $30 \mathrm{~s}$ epochs. These representations show smaller values of WPSUM13 that only increase until a limited value when WAKE or (Rapid Eye Movement) REM activities appear, as can be seen for instance between 345 and $360 \mathrm{~min}$ (WAKE stage) or between 260 and $290 \mathrm{~min}$ (REM activity). The variable WPSUM13 dynamic of a recording with OSA in a minute by minute representation is shown in Figure 4(a), where red asterisks indicates the presence or absence of apnea when values are " 1 " or " 0 ," respectively. It can be observed that higher values of the variable WPSUM13 in sleep breathing pauses are related to the presence of increased heart rate dynamics.

Although the pattern of increased WPSUM13 in tachycardias and bradycardias are very prevalent in sleep breathing disorders, some apneas are not accompanied with so clear high variability pattern probably due to lack of adequate autonomous nervous system reaction. The heart rate fluctuations are the result of a changing sympathetic tone and in some patients the sympathetic tone may not fluctuate so much due to autonomic neuropathy, cardiac disorders, or other confounding factors that can have more impact on the sympathetic tone than sleep apnea. Sleep stages can also influence the heart rate.
Logistic analysis for OSA based only on clinical and physical findings included the following variables: age, neck circumference, Epworth and loud snoring (yes/no).

Logistic analysis based on clinical measurements and symbolic dynamics, included the same clinical variables and the average value of WPSUM13 $\left(\mathrm{M}_{1}\right)$. The rest of measures $\mathrm{M}_{2}-\mathrm{M}_{6}$ did not improve the performance of the classifier.

The model of clinical variables shows that from the age of $70 \mathrm{yr}$, the probability of OSA decreases (Figure 2). This effect seems not to be kept in the model that includes the variable WPSUM13. We can say that the penalized likelihood from which the additive model estimated is complex. A forced increase of the effective degrees of freedom (reduced smoothing) shows again the same decay of the abovementioned probabilities, such as is shown in Figure 5. However, this is not the optimal model according to the Akaike criterion (Akaike Information Criterium: $\mathrm{AIC}=88.6$ versus 78.6 for the optimal model in Figure 6, the lower AIC the better is the model). This is therefore a subtle aspect on which one could justify by increasing of the sample size with patients older than $70 \mathrm{yr}$.

A previous work ${ }^{21}$ has studied the effect of age on sleep apnea. The study shows that the prevalence of sleep apnea tends to increase with age but that the clinical significance (severity) of apnea decreases.

For diagnostic rules based only on clinical and physical variables, the corresponding area under the ROC curve was 0.907 (95\% confidence interval $(\mathrm{CI})=0.848,0.967)$, (Figure $7)$. For the model including the average of WPSUM13, the area under the ROC curve was increased to 0.941
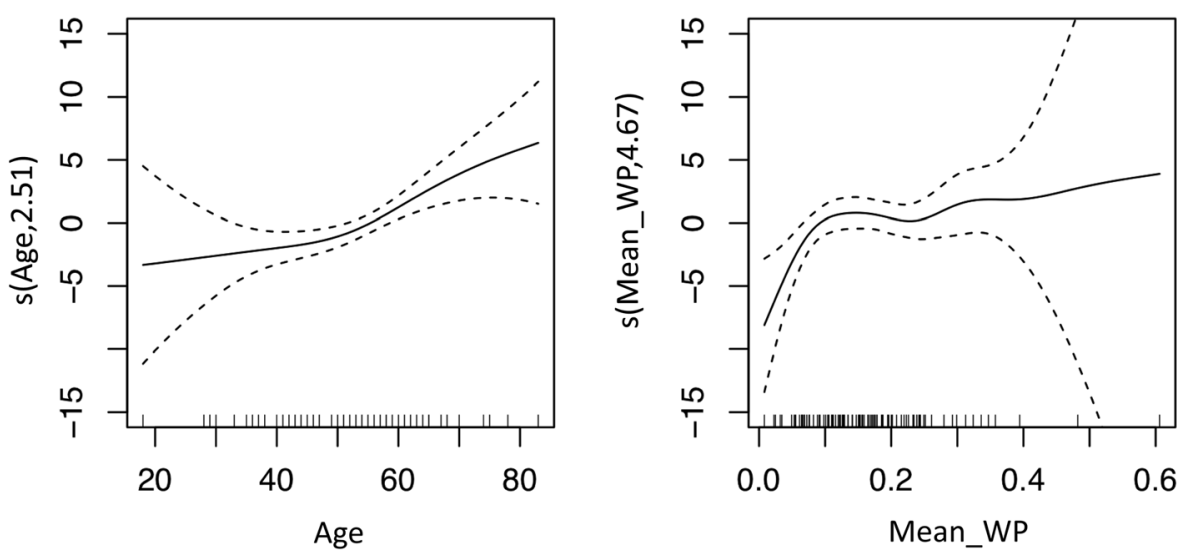

FIG. 6. Non-linear effects of the age and $M_{1}$ (Mean_WP) on the probability of OSA (- - - 95\% CI), (model based on clinical and physical variables and $M_{1}$ (Mean_WP)). $($ AIC $=78.6)$. The model that includes the variable WPSUM13 does not show a decrease on the probability of OSA. In this model, the function of age, s(age) is estimated with 2.51 degrees of freedom and s(Mean_WP) with 4.67 degrees of freedom. 


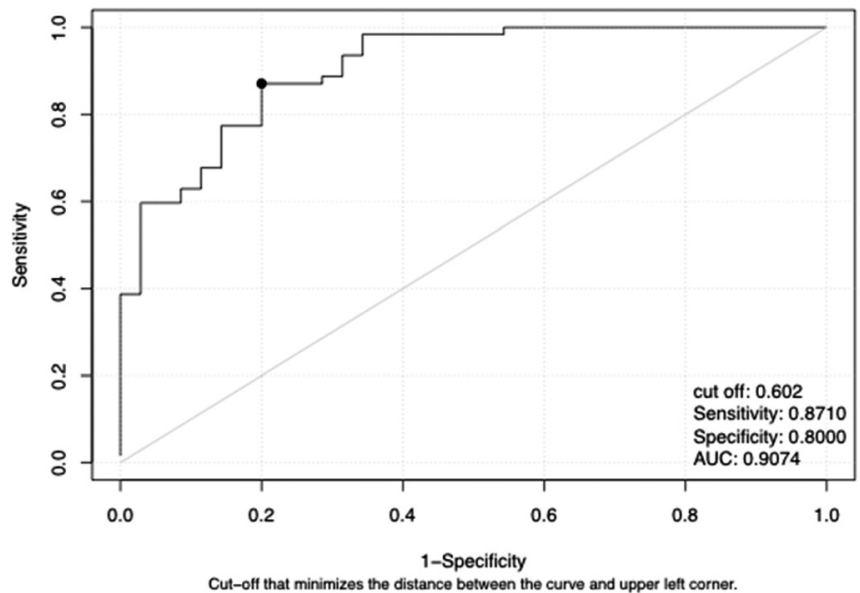

FIG. 7. ROC curve for OSA prediction based on clinical and physical variables.

$(95 \%=0.897,0.985),($ Figure 8$)$. The evaluation parameters of each of the diagnostic rules are summarized in Table III.

Alternative features from HRV in time and frequency domain have been tested. Time domain features (for example, mean RR) did not improve the results obtained only with clinical variables $(\mathrm{AIC}=85.3$, and therefore higher than the 78.6 in Figure 6). The average of mean RR calculated in five min segments does not capture relevant information about tachycardia-bradycardia pattern. Power spectral analysis features as VLF/P (calculated as the power spectrum in the VLF band $(0.0033 \mathrm{~Hz}-0.04 \mathrm{~Hz})$ divided by the total power) were also tested. Also in this case, the result obtained using the mean value of this feature calculated in $5 \mathrm{~min}$ segments, did not improve the diagnostic performance $(\mathrm{AIC}=87.0)$.

\section{DISCUSSION}

Although the screening method and variable definition are not new, this is the first contribution that innovates in the strategy to merge the features of two different sources (clinical and physical variables with symbolic dynamic from HRV). Furthermore, the use of symbolic dynamics of HRV makes possible to detect some patterns in OSA heart rhythms which are not possible to obtain by standard linear methods.

The logistic regression for OSA obtained using only clinical and physical variables have significant discriminant value (areas under the ROC curve $=0.907$ ). The model combining clinical and physical variables with information

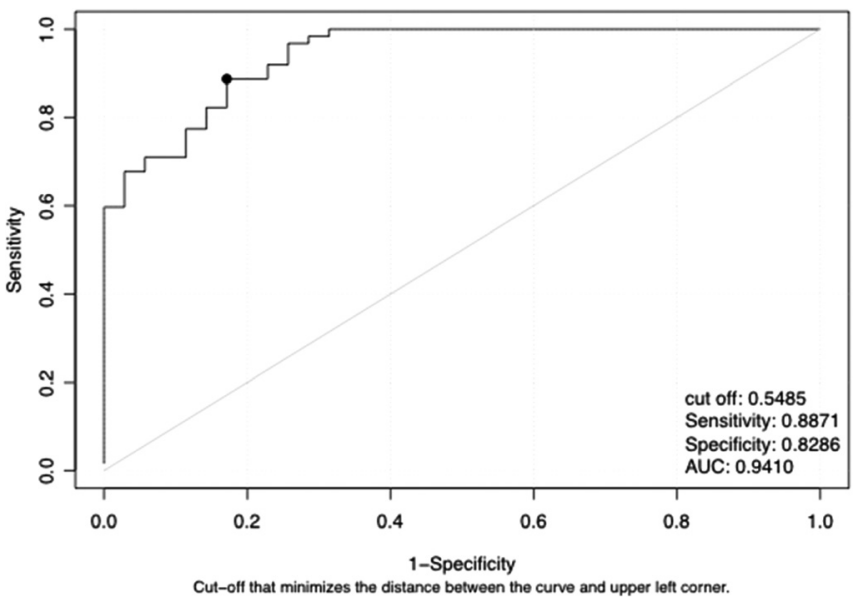

FIG. 8. ROC curve for OSA prediction based on clinical and physical variables and $M_{1}$ (Mean_WP).

provided by the variable $\mathrm{M}_{1}$ increases areas under the ROC curve to 0.941 .

Our study was limited by choosing the population among individuals with symptoms suggesting OSA and the necessity to avoid patients with heart rhythm disorders. In any case, the final rule reaches a sensitivity of $88.7 \%$ and specificity of $82.9 \%$.

This improvement in performance could be considered relevant from the economic point of view, if we take into account the number of PSG performed per year and the cost of a complete polysomnography (for example, in a standard public hospital in Spain, around 400 PSG per year and around 600 Euros per PSG).

It would be interesting to validate our model in a sample drawn from the general population, to provide physicians with a tool for screening the patients to be referred to a sleep laboratory.

The sample of our study was obtained from patients who underwent polysomnography because OSA suspicion. As shown in Table I, our patients with OSA had more heart disease, arrhythmias and cardiac treatment compared to the group of non OSA subjects; although these differences were not statistically significant, a trend toward significance was found. We think that if the size were larger, then significant levels would have been reached.

We have tested linear variables from time and frequency domains that are typically used for apnea detection. These variables did not improve the screening results. Clear

TABLE III. Multivariate logistic models for OSA (AHI $\geq 10$ ).

\begin{tabular}{|c|c|c|c|c|}
\hline \multirow[b]{3}{*}{ Factor } & \multicolumn{4}{|c|}{ Model } \\
\hline & \multicolumn{2}{|c|}{ Only clinical and physical variables } & \multicolumn{2}{|c|}{ Clinical and physical variables and $M_{1}$} \\
\hline & $\mathrm{P}^{\mathrm{a}}$ & Odd ratio $(\mathrm{OR})(95 \% \mathrm{CI})$ & $\mathrm{P}^{*}$ & OR $(95 \% \mathrm{CI})$ \\
\hline Age & $<0.001$ & Nonlinear effect & $<0.001$ & Nonlinear effect \\
\hline Neck circumference, per $\mathrm{cm}$ & $<0.001$ & $1.393[1.148 ; 1.691]$ & $<0.001$ & $1.534[1.177 ; 2.000]$ \\
\hline Epworth, per unity & $<0.001$ & $1.235[1.080 ; 1.412]$ & $<0.001$ & $1.235[1.051 ; 1.451]$ \\
\hline Loud snoring & $<0.001$ & $19.1[4.086 ; 89.2]$ & $<0.001$ & $32.9[5.4 ; 202]$ \\
\hline$M_{1}=\operatorname{Mean}\left(W P_{t}\right)$ & $\ldots$ & $\cdots$ & 0.006 & Nonlinear effect \\
\hline
\end{tabular}

${ }^{\mathrm{a}}$ Likelihood ratio test. 
instationarity of beat to beat time series during apnea was a reason for applying of nonlinear methods.

In our study, we are not supposing that HRV contains all necessary information for OSA detection. However, it has been demonstrated that if the HRV nonlinear feature is added to standard clinical and physical variable set, the method achieves acceptable performance for OSA detection and can be used for prescreening of patients to decrease numbers of PSG.

\section{ACKNOWLEDGMENTS}

This research was partially supported by Cátedra Teléfonica, Universidad de Las Palmas de Gran Canaria 2013.

${ }^{1}$ M. Riedl, A. Müller, and N. Wessel, "A practical consideration of permutation entropy,” Eur. Phys. J.: Spec. Top 222, 249-262 (2013).

${ }^{2}$ M. Ciszak and B. Michele, "Synaptic plasticity modulates autonomous transitions between waking and sleep states: Insights from a Morris-Lecar model," Chaos 21, 043119 (2011).

${ }^{3}$ A. Leite, A. P. Rocha, and M. E. Silva, "Beyond long memory in heart rate variability: An approach based on fractionally integrated autoregressive moving average time series models with conditional heteroscedasticity," Chaos 23, 023103 (2013).

${ }^{4}$ L. E. Virgilio Silva and L. Otavio Murta, Jr., "Evaluation of physiologic complexity in time series using generalized sample entropy and surrogate data analysis," Chaos 22, 043105 (2012).

${ }^{5}$ N. Wessel, M. Riedl, and J. Kurths, "Is the normal heart rate 'chaotic' due to respiration?," Chaos 19, 028508 (2009).

${ }^{6}$ T. Young, M. Palta, J. Dempsey, J. Skatrud, S. Weber, and S. Badr, "The occurrence of sleep-disordered breathing among middle-aged adults," N. Engl. J. Med. 328(17), 1230-1235 (1993).

${ }^{7}$ R. B. Berry, R. Budhiraja, D. J. Gottlieb, D. Gozal, C. Iber, V. K. Kapur, C. L. Marcus, R. Mehra, S. Parthasarathy, S. F. Quan, S. Redline, and K. P. Strohl, "Rules for scoring respiratory events in sleep: update of the 2007 AASM Manual for the scoring of sleep and associated events. Deliberations of the sleep apnea definitions task force of the American Academy of Sleep Medicine,” J. Clin. Sleep Med. 8(5), 597-619 (2012).
${ }^{8}$ N. Wessel, A. Voss, H. Malberg, Ch. Ziehmann, H. U. Voss, A. Schirdewan, U. Meyerfeldt, and J. Kurths, "Nonlinear analysis of complex phenomena in cardiological data," Herzschr. Elektrophys. 11(3), 159-173 (2000).

${ }^{9}$ J. Kurths, A. Voss, A. Witt, P. Saparin, H. J. Kleiner, and N. Wessel, "Quantitative analysis of heart rate variability," Chaos 5, 88-94 (1995).

${ }^{10}$ A. Voss, J. Kurths, H. J. Kleiner, A. Witt, N. Wessel, P. Saparin, K. J. Osterziel, R. Schumann, and R. Dietz, "The application of methods of non-linear dynamics for the improved and predictive recognition of patients threatened by sudden cardiac death," Cardiovasc. Res. 31, 419-433 (1996)

${ }^{11}$ J. Kurths, A. Witt, H. Atmansbacher, F. Feudel, H. Scheingraber, and R. Wackerbauer, General Remarks on Complexity, Inside Versus Outside, Series in Synergetics, edited by H. Atmanspacher and G. J. Dalenoort (Springer, 1994), Vol. 63, pp. 219-223.

${ }^{12}$ M. L. Appel, R. D. Berger, J. P. Saul, J. M. Smith, and R. Cohen, "Beatto-beat variability in cardiovascular variables: noise or music?," J. Am. Coll. Cardiol. 14, 1139-1148 (1989).

${ }^{13}$ R. Artuso, E. Aurell, and P. Cvitanovic, "Recycling of strange sets," Nonlinearity 3, 325-358 (1990).

${ }^{14}$ F. Lombardi, G. Sandrone, S. Pempruner, R. Sala, M. Garimoldi, S. Cerutti, G. Baselli, M. Pagani, and A. Malliani, "Heart rate variability as an index of sympathovagal interaction after acute myocardial infarction," Am. J. Cardiol. 60, 1239-1245 (1987).

${ }^{15}$ J. A. Morgan and J. F. Tatar, "Calculation of the residual sum of squares for all possible regressions," Technometrics 14, 317-325 (1972).

${ }^{16}$ N. Wessel, H. Malberg, R. Bauernschmitt, and J. Kurths, "Nonlinear methods of cardiovascular physics and their clinical applicability," Int. J. Bifurcation Chaos Appl. Sci. Eng. 17, 3325-3371 (2007).

${ }^{17}$ D. Cysarz, A. Porta, N. Montano, P. V. Leeuwen, J. Kurths, and N. Wessel, "Quantifying heart rate dynamics using different approaches of symbolic dynamics,” Eur. Phys. J.: Spec. Top. 222(2), 487-500 (2013).

${ }^{18}$ H. Akaike, "A new look at the statistical model identification," IEEE Trans. Autom. Control 19(6), 716-723 (1974).

${ }^{19}$ T. Hastie and R. Tibshirani, "Generalized additive models," Stat. Sci. 3, 295-416 (1986).

${ }^{20} \mathrm{R}$ Development Core Team, $R:$ A Language and Environment for Statistical Computing (R Foundation for Statistical Computing, Vienna, Austria, 2012), see http://www.R-project.org/.

${ }^{21}$ E. O. Bixler, A. N. Vgontzas, T. Ten Have, K. Tyson, and A. Kales, "Effects of age on sleep apnea in men: I. Prevalence and severity," Am. J. Respir. Crit. Care Med. 157(1), 144-148 (1998). 